\title{
PEMBENTUKAN DAN PELAKSANAAN KELOMPOK PENDUKUNG ASI (KP ASI) DI RW 2 KELURAHAN SIALANG SAKTI WILAYAH KERJA PUSKESMAS REJOSARI KECAMATAN TENAYAN RAYA PEKANBARU TAHUN 2019
}

\author{
Fatiyani Alyensi*1, Ani Laila ${ }^{2}$ \\ 1,2Prodi D III Kebidanan, Jurusan Kebidanan, Poltekkes Kemenkes Riau \\ *E-mail: fatiyeni@pkr.ac.id
}

\begin{abstract}
The World Health Organization (WHO) in 2009 and the American Academy of Pediatrics $(A A P)$ in 2012 recommended the provision of optimal nutrition for newborns, namely a global strategy of exclusive breastfeeding for 6 months. Giving exclusive breastfeeding is still not on target can have an impact on psychomotor, cognitive, and social disorders as well as clinically impaired growth. Data from the Riau Province Health Service in 2015 stated that the coverage of exclusive milk in Riau Province was $68.8 \%$ and the data from the Pekanbaru City Health Service in 2015 was 71.3\%. Based on data from the Rejosari Community Health Center in Sialang Sakti Village in 2018, the achievement of exclusive breastfeeding was only 43.8\%, the lowest achievement in the Pekanbaru city area. Some cadres in this work area have received little exposure regarding exclusive breastfeeding, but the coverage of exclusive breastfeeding is still low. And it is necessary to establish and assist the formation of KP-ASI as community service for the working area of the Rejosari Community Health Center, Sialang Sakti Sub-district, Tenayan Raya District in 2019. The aim of this community service is to form and increase the knowledge and skills of the ASI support group (KP-ASI). The targets are pregnant women, breastfeeding and cadres totaling 11 people. The activity was carried out from May - July 2019. The result was an increase in the knowledge of ASI KP mothers on Early Breastfeeding Initiation (IMD) material from an average of 60 to 80, an increase in knowledge of ASI KP mothers on breastfeeding material from an average of 70 to 90, increased skills Mrs. ASI in giving KIE, namely 83.75. It is recommended to have assistance from the Rejosari Community Health Center in every ASI support group activity and continued community service activities by monitoring monitoring and evaluating
\end{abstract}

Keywords-Group, Supporting ASI, Exclusive ASI, Sialang Sakti

\begin{abstract}
Abstrak
World Health Organization (WHO) tahun 2009 dan America Academy of Pediatric (AAP) tahun 2012 merekomendasikan pemberian nutrisi yang optimal bagi bayi baru lahir yakni dengan strategi global pemberian ASI eksklusif selama 6 bulan. Pemberian ASI eksklusif masih belum sesuai target dapat berdampak pada gangguan psikomotor, kognitif, dan sosial serta secara klinis terjadi gangguan pertumbuhan. Data Dinas Kesehatan Provinsi Riau tahun 2015 menyebutkan cakupan ASI eksklusif Provinsi Riau sebesar 68,8 \% dan data Dinas Kesehatan Kota Pekanbaru tahun 2015 sebesar 71,3\%. Berdasarkan data di Puskesmas Rejosari di Kelurahan Sialang Sakti tahun 2018 bahwa capaian ASI Ekslusif hanya sebesar 43,8\%, merupakan capaian yang paling rendah diwilayah kota Pekanbaru. Beberapa kader diwilayah kerja ini sudah pernah mendapat sedikit paparan mengenai ASI Ekslusif namun cakupan pemberian ASI Ekslusif masih rendah. Dan perlu dilakukan Pembentukan dan Pembinaan KP-ASI sebagai pengabdian masyarakat untuk wilayah kerja Puskesmas Rejosari Kelurahan Sialang Sakti Kecamatan Tenayan Raya tahun 2019. Tujuan pengabdian masyarakt ini adalah terbentuknya dan meningkatkan pengetahuan serta keterampilan Kelompok pendukung ASI (KP-ASI). Sasaran adalah ibu hami, menyusui dan kader yang berjumlah 11 orang. Kegiatan dilaksanakan dari bulan Mei - Juli 2019. Hasilnya terdapat peningkatan pengetahuan ibu KP ASI pada materi Inisiasi Menyusu Dini (IMD) dari rata-rata 60 menjadi 80, peningkatan pengetahuan ibu KP ASI pada materi menyusui dari rata-rata 70 menjadi 90, peningkatan keterampilan ibu KP ASI dalam memberikan KIE yaitu
\end{abstract}


DINAMISIA - Jurnal Pengabdian Kepada Masyarakat Vol. 3, No. 2 Desember 2019, Hal. 299-304

83.75. Disarankan adanya pendampingan dari pihak Puskesmas Rejosari dalam setiap kegiatan kelompok pendukung ASI dan dilanjutkan kegiatan pengabdian masyarakat dengan monitoring dan evaluasi KP ASI.

Kata Kunci-Kelompok, Pendukung ASI, ASI Eksklusif, Sialang Sakti

\section{PENDAHULUAN}

Air Susu Ibu (ASI) merupakan makanan terbaik bagi bayi karena mengandung komposisi gizi yang paling lengkap sehingga penting bagi tumbuh kembang yang optimal baik fisik maupun mental dan kecerdasan bayi. Pemberian ASI akan berhasil apabila ada komitmen ibu untuk memberikan ASI, dilaksanakan secara dini (early initiation), posisi menyusui yang benar, menyusukan atas permintaan bayi (on demand), serta diberikan secara eksklusif [1]. Berdasarkan laporan Direktorat Jendral (Ditjen) Gizi dan KIA Kemenkes tahun 2015, cakupan pemberian ASI pada umur 0-6 bulan masih cukup rendah yaitu sebesar 52,3\%. Angka tersebut belum mencapai target pemberian ASI eksklusif tahun 2015 sebesar 80\% [2]. Data Dinas Kesehatan Provinsi Riau tahun 2015 menyebutkan cakupan ASI eksklusif Provinsi Riau sebesar 68,8 \% dan data Dinas Kesehatan Kota Pekanbaru tahun 2015 sebesar 71,3\%.[3]

Berdasarkan data di Puskesmas Rejosari di Kelurahan Sialang Sakti tahun 2018 bahwa capaian ASI Ekslusif hanya sebesar 43,8\%, merupakan capaian yang paling rendah diwilayah kota Pekanbaru. Beberapa kader diwilayah kerja ini sudah pernah mendapat sedikit paparan mengenai ASI Ekslusif namun cakupan pemberian ASI Ekslusif masih rendah. Dan perlu dilakukan Pembentukan dan Pembinaan KP-ASI sebagai pengabdian masyarakat untuk wilayah kerja Puskesmas Rejosari Kelurahan Sialang Sakti Kecamatan Tenayan Raya tahun 2019.

Berdasarkan hasil penelitian Bekti (2016) di Temanggung menunjukkan bahwa kelompok yang mendapat dukungan KP-ASI sebagian besar $(86,4 \%)$ memberikan ASI secara eksklusif sedangkan kelompok dengan pemberian leaflet hanya sebagian kecil $(31,8 \%)$ yang memberikan ASI secara eksklusif. Kesimpulan penelitian ini adalah pembentukan kelompok pendukung ASI eksklusif efektif terhadap perilaku pemberian ASI eksklusif ( $p$ value 0,0001).[4]

Pada Tahun 2019 kegiatan pengabdian masyarakat dosen Prodi D III Kebidanan dilaksanakan di Kelurahan Sialang Sakti Kecamatan Tenayan Raya Wilayah Kerja Puskesmas Rejosari. Agar ibu-ibu dapat lebih berhasil menyusui diperlukan dukungan keluarga, penyuluhan dan pengetahuan praktis dari petugas atau kader. Oleh karena itu perlu maka diperlukan salah satu upaya yang ditempuh adalah dengan Pembentukan dan Pembinaan Kelompok Pendukung ASI sebagai pengabdian masyarakat di RW 2 Kelurahan Sialang Sakti wilayah kerja Puskesmas Rejosari tahun 2019

\section{METODE}

Kegiatan pengabdian masyarakat ini dilaksanakan pada bulan April sampai Juli 2019. Lokasi dilaksanakan di RW 02 Kelurahan Sialang Sakti Kecamatan Tenayan Raya Pekanbaru.

2.1 Edukasi pada KP ASI

Edukasi Yang dilaksanakan yaitu : IMD, ASI secara ekslusif, manfaat ASI bagi tumbuh kembang anak, cara atau teknik menyusui yang benar, pentingnya support dari keluarga dan orang - orang terdekat bagi ibu menyusui serta pentingnya pembentukan kelompok pendukung ASI dengan metode belajar ceramah, tanya jawab, peragaan/praktek, curah pendapat dan simulasi.

2.2 Praktik edukasi KP ASI

Praktik edukasi KP ASI dilaksanakan pada ibu hamil, nifas dan menyusui yang didampingi oleh konselor KP ASI dengan metode home visit. 


\subsection{Monitoring dan evaluasi}

Kegiatan Monitoring dan Evaluasi KP ASI dilaksanakan oleh reviewer dan tim Pengabmas Poltekkes Riau dengan metode bed side teaching

\section{HASIL DAN PEMBAHASAN}

Kegiatan pada pertemuan pertama adalah pembentukan Kelompok Pendukung ASI. Sebelumnya kader dan ibu menyusui diberi penjelasan pengertian, tujuan, manfaat, program dan pentingnya KP ASI dalam mendukung program Pemerintah dalam meningkatkan cakupan ASI Ekslusif. Setelah ibu mengerti dan bersedia maka dibentuklah Kelompok Pendukung ASI yang yang diberi nama "Bintang Berpasang Sirih Adat". Peserta berjumlah 11 orang.

Kegiatan KP ASI pada pertemuan pertama adalah pemberian materi tentang Inisiasi Menyusu Dini (IMD) dan Menyusui. Sebelum materi diberikan peserta diberikan pre test mengenai IMD dengan 10 pertanyaan dan menyusui 10 pertanyaan. Hal ini bertujuan untuk menilai sejauh mana pengetahuan ibu sebelum materi diberikan. Selanjutnya tim memberikan materi mengenai ASI Eksklusif, anatomi payudara, reflek menyusui, masalah bagi ibu dan bayi dalam menyusui dan cara mengatasinya. Peserta diberi modul Petunjuk Praktik bagi Kelompok Pendukung ASI dalam Mendampingi Ibu Menyusui sehingga memudahkan dalam menerima materi. Materi diberikan selama 60 menit dengan menggunakan madia infokus dan dilanjutkan dengan sesi tanya jawab. Diakhir sesi peserta diberikan lembar post test yang bertujuan untuk melihat sejauh mana peningkatan pengaetahuan peserta dalam pertemuan ini.

Tabel 3.1 Rata-rata Pengetahuan Ibu KP ASI sebelum dan sesudah diberi pengetahuan tentang IMD dan menyusui

\begin{tabular}{lccc}
\hline Materi & $\mathrm{n}$ & $\begin{array}{c}\text { Rata-rata } \\
\text { Nilai Pre Test }\end{array}$ & $\begin{array}{c}\text { Rata-rata } \\
\text { Nilai Post Test }\end{array}$ \\
\hline IMD & 11 & 60 & 80 \\
Pemberian ASI & & 70 & 90 \\
\hline
\end{tabular}

Berdasarkan tabel 3.1 terdapat peningkatan pengetahuan peserta pada materi IMD dari 60 menjadi 80 dan materi pemberian ASI dari 70 menjadi 90.

Kegiatan pada pertemuan kedua adalah praktik phantom. Tujuan praktik adalah agar peserta dapat mempraktikkan langsung pada phantom cara menyusui yang baik dan benar, perawatan payudara, pijat oksitosin, cara memerah ASI dan mengatasi masalah dalam menyusui. Apabila ditemukan masalah didalam pendampingan ibu KP ASI dapat membantu ibu hamil dan menyusui dalam melakukan praktik. Dalam melakukan praktik tim dibantu oleh mahasiswa dengan teknik demonstrasi pada phantom payudara dan bayi. Setelah melihat tim dan mahasiswa melakukan praktik peserta langsung mencoba mempraktikkan sampai bisa. Selanjutnya dilakukan penilaian keterampilan dengan menggunakan lembar pengamatan dan dinilai sejauh mana keterampilan peserta didalam melakukan praktik.

Tabel 3.2 Rata-rata keterampilan ibu KP ASI dalam praktik pada phantom

\begin{tabular}{lcc}
\hline \multicolumn{1}{c}{ Praktik } & $\mathrm{n}$ & Nilai Rata-rata \\
\hline Perawatan payudara & 11 & 80 \\
Cara Menyusui yang baik dan benar & & 85 \\
Pijat Ositosin & 80 \\
Cara Memerah ASI & 90 \\
\hline Rata-rata & 83.75 \\
\hline
\end{tabular}

Berdasarkan tabel 3.2 terlihat bahwa keterampilan ibu KP ASI dalam melakukan praktik yaitu 83.75 yaitu diatas batas minimal yaitu 75 sehingga sudah dinyatakan lulus dalam praktik.

Kegiatan KP ASI pada pertemuan ketiga adalah pemberian materi tentang Konseling pada ibu hamil dan menyusui. Kegiatan ini bertujuan untuk memberikan pembekalan kepada peserta 
agar mudah dalam melakukan komunikasi konseling pada saat melakukan pendampingan ASI. Peserta diberi materi tentang pengertian konseling, KIE, komunikasi efektif, kesulitan dalam konseling dan KIE pada ibu hamil dan menyusui. Setelah itu peserta melakukan praktik konseling pada ibu hamil dan menyusui dengan menggunakan bantuan media lembar balik konseling KP ASI. Selanjutnya tim melakukan role play terlebih dahulu untuk memberikan contoh kepada peserta cara melakukan konseling yang benar menurut SOLER. Selanjutnya peserta mencoba melakukan role play dengan menggunakan bantuan instrument lembar pengamatan konseling menurut SOLER. Pada saat praktik peserta menyatakan awalnya sulit untuk memulai pembicaraan dengan ibu menyusui. Setelah praktik konseling peserta lain akan memberikan masukan dan saran sesuai dengan lembar pengamatan yang ada.

Kegiatan praktik KIE oleh ibu kader pada ibu hamil, nifas dan menyusui dilakukan dengan menggunakan lembar observasi KIE (lembar observasi terlampir). Praktik KIE didampingi oleh 2 orang konselor Tim Pengabmas Poltekkes Kemenkes Riau. Praktik KIE dilaksanakan sebanyak 1x pertemuan pada ibu menyusui di rumah ibu nifas di RW2. Peserta praktik KIE yaitu 5 orang ibu nifas dan menyusui.

Selama pelaksanaan praktik KIE ditemui beberapa kendala oleh peserta KP ASI diantaranya adalah : Ibu KP ASI kurang menguasai cara mengatasi masalah- masalah dalam menyusui, sebagai solusinya konselor memberikan modul dan lembar balik KP ASI selama memberikan konseling, ibu menyusui kurang memberikan feed back sehingga tidak terjalin komunikasi dua arah seperti yang diharapkan sehingga sulit untuk mengevaluasi jalannya KIE, lingkungan yang kurang kondusif dalam melakukan praktik KIE seperti ruangan tidak nyaman, tempat yang bising.

Evaluasi dilaksanakan dalam bentuk Fokus Group Diskusi (FGD) antara Tim Pengabmas dan ibu KP ASI pada pertemuan terakhir tanggal 29 Juli 2019. Evaluasi dilakukan di Posyandu RW. 12 KelurahanSialang Sakti. Dalam hal ini juga dilakukan diskusi interaktif diantara peserta dengan menceritakan pengalaman dalam melakukan KIE pada ibu hamil, nifas dan menyusui. Pengalaman berupa kemudahan dan kesulitan dalam melakukan KIE cara menyusui,cara perawatan payudara dan masalah didalam menyusui. Dalam diskusi ini peserta akan saling berbagi pengalaman dalam mengatasi masalah yang dihadapi selama KIE. Dalam diskusi ini, tim pengabmas akan membantu ibu dalam memecahkan permasalahan yang ditemukan dengan cara memberikan materi KIE dan praktik langsung pada sesama peserta dalam melakukan KIE. Kendala yang ditemukan selama praktik adalah perlunya keterampilan dalam memberikan konseling pada ibu menyusui yang tertutup dan tidak mau menerima masukan atau saran dari ibu KP ASI. Berdasarkan evaluasi Tim Pengabmas merasa perlu memberikan support untuk kelancaran memberikan KIE tentang menyusui dalam bentuk ;modul KP ASI, leaflet menyusui, teknik konseling pada saat- saat sulit dalam konseling. Dari hasil FGD dan pengamatan tim ditemukan bahwa kelompok KP ASI Kelurahan Sialang Sakti dalam melakukan praktik KP ASI belum bisa melakukan pendampingan pada ibu hamil, menyusui dan nifas secara maksimal karena baru pertama kali melakukan praktik sehingga perlu dilakukan monitoring dan evaluasi oleh tim dan bidan agar pelaksanaan KP ASI bisa dilaksanakan dengan baik.
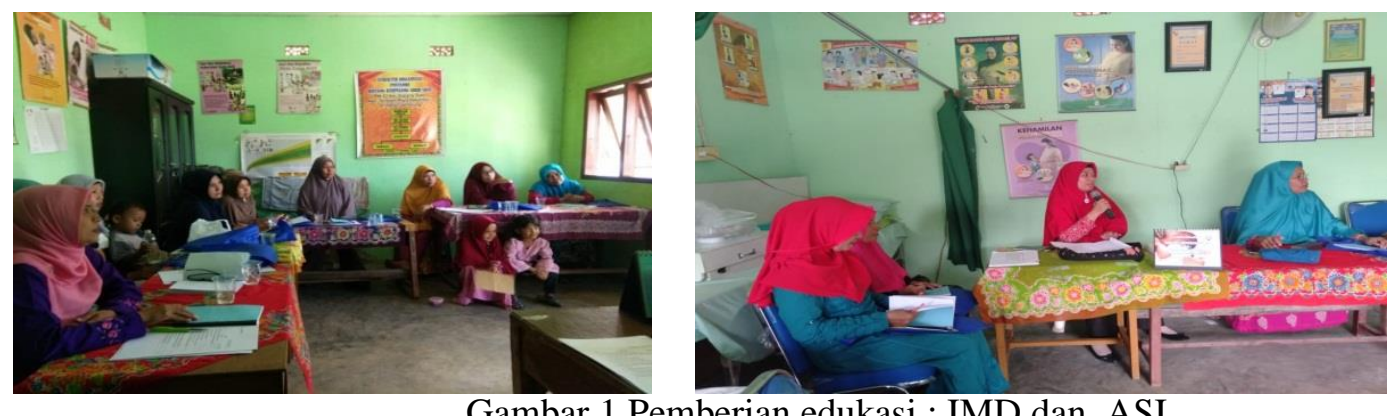

Gambar 1 Pemberian edukasi : IMD dan ASI 

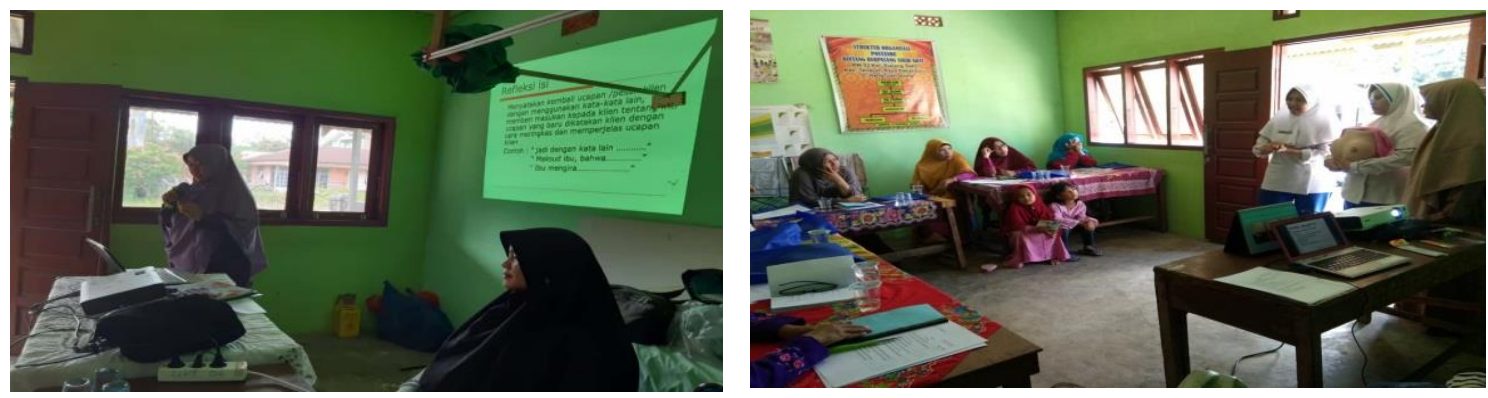

Gambar 2 Edukasi Konseling dan Praktik phantom
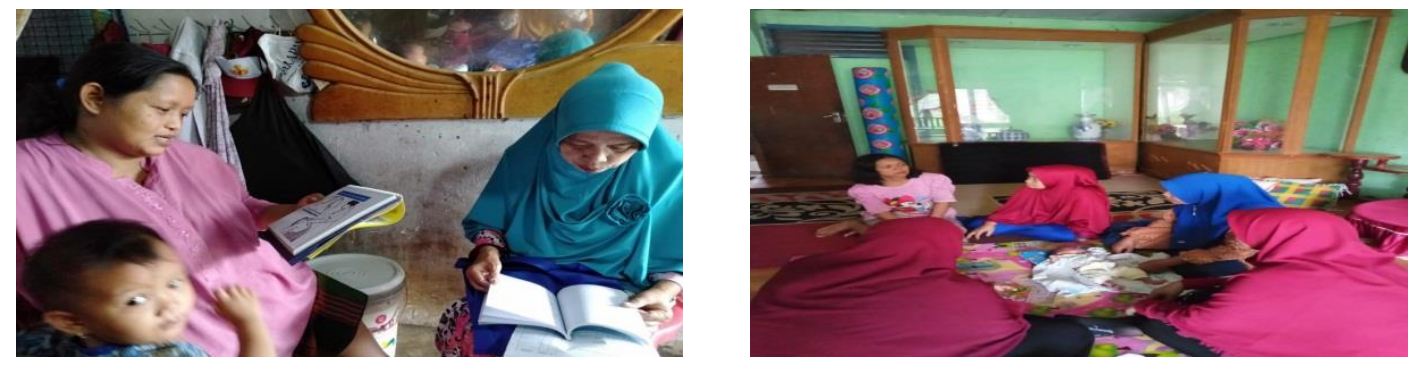

Gambar 3 Peran KP ASI pada ibu menyusui

4.

KESIMPULAN

Berdasarkan kegiatan pengabmas KP AI yang telah dilaksanakan di RW 2 Keluarahan Sialang Sakti Wilayah Kerja Puskesmas Rejosari Kota Pekanbaru selama 4 bulan dapat disimpulkan bahwa:

1. Terbentuknya Kelompok Pendukung ASI (KP ASI) "Bintang Berpasang Sirih Adat"

2. Peningkatan pengetahuan ibu KP ASI pada materi Inisiasi Menyusu Dini (IMD) dari rata-rata 60 menjadi 80.

3. Peningkatan pengetahuan ibu KP ASI pada materi menyusui dari rata-rata 70 menjadi 90.

4. Peningkatan keterampilan ibu KP ASI dalam memberikan KIE yaitu 83.75

\section{SARAN}

Perlu adanya pendampingan dari pihak Puskesmas Rejosari terutama bidan koordinator dalam setiap kegiatan kelompok pendukung ASI agar program tersebut dapat berjalan lancar.

\section{UCAPAN TERIMA KASIH}

Penulis mengucapkan terima kasih kepada Poltekkes Kemenkes Riau yang telah memberi dukungan dana terhadap pengabdian kepada masyarakat ini.

\section{DAFTAR PUSTAKA}

[1] Roesli, Utami. 2007. Mengenal ASI Eksklusif. Jakarta.Trubus Agriwidya.

[2] Kemenkes.2015. Ditjen Gizi dan

[3] Dinkes Kota Pekanbaru. 2016. Profil Kesehatan Kota Pekanbaru Tahun 2015

[4] Yuniyani,bekti dkk.2017. Efektifitas Kelompok Pendukung ASI (KP-ASI) Eksklusif terhadap Perilaku Pemberian ASI Eksklusif. Jurnal Ilmiah Bidan. Vol 11 no.1 Tahun 2017

[5] Saleha,S. 2009. Asuhan kebidanan pada masa nifas. Jakarta:Salemba Medika.

[6] Tim program Heathy start-Mercy Corps Indonesia, Panduan dasar pembina motivator menyusui, Mercy Corps, 2008 
DINAMISIA - Jurnal Pengabdian Kepada Masyarakat Vol. 3, No. 2 Desember 2019, Hal. 299-304

[7] Tim program Heathy start-Mercy Corps Indonesia, 10 Topik Umum Diskusi Kelompok Pendukung Ibu, Mercy Corps, 2008

[8] Wahyudin Sumpeno, Menjadi Fasilitator Genius; Kiat Kiat Mendampingi Masyarakat, Pustaka Pelajar Yogyakarta, 2009

[9] Varney, Helen, Jan M. Kriebs, Dan Carolyn L. Gegor. 2008. Buku ajar asuhan kebidanan. Jakarta: EGC

[10] Yuniyanti, bekti. 2016. Efektivitas Kelompok Pendukung Asi (Kp-Asi) Eksklusif Terhadap Perilaku Pemberian Asi Eksklusif . Jurnal Ilmiah Bidan. Volume 2 No. 1 